\title{
Postprint
}

Published in Composites Science and Technology, vol 193, 108126, 2020

DOI: https://doi.org/10.1016/j.compscitech.2020.108126

\section{Delamination resistant composites by interleaving bio-based long- chain polyamide nanofibers through optimal control of fiber diameter and fiber morphology}

Timo Meireman ${ }^{1}$, Lode Daelemans ${ }^{1}$, Sander Rijckaert ${ }^{1}$, Hubert Rahier ${ }^{2}$, Wim Van Paepegem ${ }^{1}$ and Karen De Clerck*1

${ }^{1}$ Department of Materials, Textiles and Chemical Engineering (MATCH), Ghent University, Technologiepark 907, B-9052 Zwijnaarde, Belgium

${ }^{2}$ Department Materials and Chemistry, Vrije Universiteit Brussel, Pleinlaan 2, B-1050 Brussels, Belgium

*Karen.DeClerck@UGent.be Tel.: +3292645740Fax.: +3292645846

\section{Abstract}

In this work an innovative electrospinning system is proposed that simultaneously has an adequate temperature resistance, a high increase in mode I $(+51 \%)$ and mode II $(+96 \%)$ delamination performance and can be commercially produced. Interleaving nanofibrous veils can potentially solve the issue of the limited delamination resistance encountered in composite laminates, but industrial upscaling has always been impeded by one or more critical factors. These constraining factors include a limited temperature stability of the nanofibers, a lack in simultaneous mode I and II delamination performance increase and the complexity of the electrospinning system because non-commercial polymers or specialty nanofibers (e.g. coaxial) are required. In this paper, a robust electrospinning system is proposed that is the first to overcome all major hurdles to make nanofiber toughening industrially viable. A new class of nanofibers based on biosourced polyamide 11 and its poly(ether-block-amide) co-polymers is used to deal with those shortcomings. The nanofibers have tuneable diameters down to $50 \mathrm{~nm}$ and cross-section morphologies ranging from circular to ribbon-shaped. The key to this work is the fundamental underpinning of the toughening effect using a broad range of interleaves with different mechanical and thermal properties, fiber diameters and fiber morphologies, all produced from the same bio-based base polymer. Generally, round and thin nanofibers performed better than larger and ribbon-like fibers. The relationship between the fiber morphology and the delamination performance is further underpinned using detailed analysis of the fracture surface. Ultimately, this results in a range of optimized nanofibrous veils capable of improving the delamination resistance considerably without suffering from the aforementioned drawbacks.

Keywords: Nano composites, matrix cracking, Fiber/matrix bond, Fiber bridging, Poly(etherblock-amide) (PEBA) 


\section{Introduction}

Today, fiber-reinforced composites are often the material of choice in high-end applications as they combine low weight, high stiffness and strength. They are commonly used in aerospace, ultralight vehicles, modern windmills and in all kinds of sports equipment. However, the susceptibility to delamination of composite laminates is still an important issue in many applications. A novel methodology to increase the interlaminar fracture toughness (IFT) is based on the interleaving of thin nanofibrous veils within the composite laminates and has proven to be an easy and straightforward pathway to toughened composites [1-10]. The nanofibers typically have a diameter below $500 \mathrm{~nm}$ and these are deposited via electrospinning as a non-woven veil with a very high surface area to volume ratio and provide superior mechanical performance compared to the bulk polymer $[4,5]$.

Nanofiber toughening of composites has been studied for a variety of polymer types, e.g. PA46, PA6, PA66, PAN, PCL, PVA, PVB, PVDF [5-14]. Some of the most frequently occurring limitations of this toughening method stem directly from the choice of polymer. Indeed, a widely reported system such as polycaprolactone (PCL) nanofibers for example have proven high increases in both mode I and mode II IFT, but have a melting point of around $55^{\circ} \mathrm{C}$. This restricts their use to room-temperature curing composites or at least require a pre-curing step around room temperature if the nanofiber structure needs to be retained [4-6,15,16]. PCL can be used for composite toughening through phase separation as well, but this decreases other mechanical properties such as elastic modulus and tensile strength as it is shown by Dadfar et al. [17]. With the type of highly relevant high-end epoxy resin used in this manuscript, a pre-curing step would be required as has been thoroughly shown in our previous research $[4,14,15]$.

On the other hand our work on temperature stable nanofibers made from commercially available polyamide resins resulted in an excellent mode II IFT increase $(+80 \%)$ for polyamide 6 , polyamide 6.6 and polyamide 6.9 , but the mode I increase was limited, likely caused by a lack of matrix adhesion [5-7,14]. Although other researchers have booked more success using polyamide nanofibers, e.g. [18,19], these results could not be reproduced by us without providing the polyamide nanofibers with a matrix-compatible shell made from polycaprolactone to increase its adhesion with the matrix $[14,16]$. The interplay of the nanofiber intrinsic mechanical properties and the adhesive interaction with the matrix material is thus highly important as pointed out by several research groups as well [5,6,20-23].

In addition, we expect that the fiber morphology of the nanofibers (diameter and cross-sectional shape) will affect their performance to increase the delamination resistance of interleaved laminates. The nanofibers absorb delamination energy by straining. A smaller nanofiber thus absorbs less energy (proportional to the cross-sectional area) which might make its adhesion to the matrix sufficient (proportional to the surface area). Although finer nanofibers were reported by several researchers to result in more stable crack propagation and better mechanical performance under flexure loading, they did not lead to an additional increase in mode I and mode II IFT 
$[9,20,24]$. On the other hand, Our earlier work on polycaprolactone did show a slight positive effect of using nanofibers (diameter $370 \mathrm{~nm}$ ) over microfibers (diameter $8.4 \mu \mathrm{m}$ ) [4]. These findings thus indicate the need for further investigation into the link between the fiber morphology aspects and the delamination performance.

It is clear nanofibrous veils are very promising toughening materials but a widespread use requires temperature-stable nanofibrous systems, that yet offer the appropriate intrinsic mechanical properties and the adhesive matrix interaction. Recently, we proposed a method to successfully achieve temperature-stable nanofibers with improved delamination resistance [14], based on dedicated coaxial nanofibers. However, application-wise, it would be more interesting if single component nanofibers are used made from commercially available polymers. Therefore, the present paper focuses on polyamide 11 (PA11) based polymers as they are expected to provide a higher ductility and toughness than polyamides like PA6 and PA6.6 due to their long aliphatic flexible backbone segment, with melting points of up to $185^{\circ} \mathrm{C}$. In addition the use of bio-sourced PA11 and three PA11-based poly(ether-block-amide)s (PEBA) with varying mechanical and electrospinning properties allows for a versatile platform of widely applicable temperature-stable nanofibers for composite toughening. However, at present, no safe eco-friendly method is available to obtain large PA11 nanofibrous veils due to the limited solubility of PA11.

In the present paper, we first develop an innovative solvent system that has low toxicity and is sufficiently stable for large-scale electrospinning of both PA11 and the PEBA polymers and thus industrially relevant. The PEBA (co)polymers are PA11-based but are chemically different from one another by their ether content, resulting in a variety in mechanical properties. By additionally altering the polymer concentration in the solvent system we produce nanofibers with a large range of properties and fibrous morphologies (diameter, cross-section shape), which are analysed for their mode I and mode II IFT performance. Fractography of these specimens is subsequently used to relate this delamination performance to the responsible micromechanisms. The understanding of these mechanisms is crucial to ultimately choose the appropriate nanofiber veils that are temperature stable, eco-friendly and commercially viable while allowing a high improvement in both mode I and mode II delamination resistance. 


\section{Materials and methods}

\subsection{Solvent study}

Preliminary solvent studies, each combining formic acid with another solvent, were performed at various temperatures in order to dissolve $8 \mathrm{wt} \%$ PA11. Formic acid was combined with each of the following thirty solvents. The selection was based on Hansen Solubility Parameters and lowtoxicity solvents which are not stated in the list of dangerous substances restricted by REACH in Annex XVII [30] (more details in Supplementary Information S1): acetic acid, acetone, anisole, benzyl alcohol, butyl acetate, n-butanol, s-butanol, t-butanol, butanone, $\gamma$-butyrolactone, cyclohexanone, diethyl ether, diethylene succinate, dimethyl sulfoxide, dioxolan, ethanol, heptane, isoamyl alcohol, lactic acid (purity $\geq 90 \%$ ), limonene (purity $\geq 97 \%$ ), ethanol, methyl tert-butyl ether, methyl isobutyl ketone, n-propanol, propionic acid, n-propyl acetate, propylene carbonate, propylene glycol, toluene, $\alpha, \alpha, \alpha$-trifluorotoluene. All solvents were ordered at Sigma-Aldrich and have a purity above $98 \%$ unless otherwise mentioned. Most of the solutions needed temperatures of $60^{\circ} \mathrm{C}$ or above to dissolve the polymer and precipitated at room temperature. Only an anisole (An) / formic acid (FA) solvent system is able to keep PA11 dissolved at room temperature. Therefore, this solvent system was further analysed with the aid of turbidity measurements (Crystal 16, Avantium Technologies) of 8wt\% PA11 solutions with different FA/An ratios. This showed that a $60 \% \mathrm{FA} / 40 \%$ An solution provides the best solubility.

\subsection{Nanofiber veil preparation}

PA11 and PA6 pellets were purchased from Sigma - Aldrich. The three poly(ether-block-amide)s: (1) Pebax ${ }^{\circledR}$ Rnew ${ }^{\circledR}$ 40R53 SP 01 resin [PEBA 40], (2) Pebax ${ }^{\circledR}$ Rnew ${ }^{\circledR} 63 R 53$ SP 01 resin [PEBA 63] and (1) Pebax ${ }^{\circledR}$ Rnew ${ }^{\circledR} 72$ R53 SP 01 resin [PEBA 72] were kindly received from Arkema. The PEBA polymers are named in increasing order of stiffness and PA11 content, PEBA40, PEBA63, PEBA72. The mechanical and thermal properties of the polymers are included in Table 1. The pellets were dissolved for electrospinning in a mixture of $60 \%$ formic acid (FA) and $40 \%$ anisole (An), both purchased from Sigma - Aldrich. Both solvents are used as received. The resulting viscosities of the electrospinning solutions are added in the Supplementary Information (SI).

An in-house developed electrospinning machine based on a rotating drum design was used to deposit the nanofibrous directly onto a glass fiber plie at $6 \mathrm{~g} / \mathrm{m}^{2}$. The areal weight and the nanofibre diameter distribution of the produced nanofibrous veils was determined at several locations throughout the membrane prior to insertion within the composites in order to ensure constant fibre properties and a homogeneous areal density of the membrane throughout the composite. PA11 was electrospun from solution at a rate of $1 \mathrm{ml} / \mathrm{h}$ while PEBA was electrospun at $2 \mathrm{ml} / \mathrm{h}$. A $6 \mathrm{~cm}$ tip-tocollector-distance was used. A high voltage power supply (Glassman High Voltage Series) was used to apply voltage in the range of $25-30 \mathrm{kV}$ for stable electrospinning. Nanofibers were produced at $23 \pm 2{ }^{\circ} \mathrm{C}$ and $50 \pm 10 \% \mathrm{RH}$. Representative SEM images were taken and nanofiber 
diameters were measured on dry samples prior to resin infusion. The nanofiber diameter and the width of ribbon shaped fibers was measured on at least 50 fibers with the software package ImageJ resulting in adequate comparisons between different membranes [31]. More details on viscosities and other aforementioned electrospinning conditions can be found in SI-S2.

Table 1 Thermal and mechanical properties of the polymers. Values denoted with '*' are according to CES EduPack (Granta Design, commercial database of material properties). Values tagged with '**' are obtained by own DSC measurements. All other values are according to the datasheet of the product. The DSC curves are added in the Supplementary Information (SI).

\begin{tabular}{lccccccc} 
& \multicolumn{3}{c}{ nanofiber } & bulk & \multicolumn{3}{c}{ datasheet } \\
Polymer & $\operatorname{Tg}\left({ }^{\circ} \mathrm{C}\right)$ & $\operatorname{Tm}\left({ }^{\circ} \mathrm{C}\right)$ & $\operatorname{Tm}\left({ }^{\circ} \mathrm{C}\right)$ & $\mathrm{E}(\mathrm{MPa})$ & $\varepsilon(\%)$ & $\varepsilon(\%)$ & $\boldsymbol{\sigma}$ at break (MPa) \\
\hline PA6 & $44-56^{*}$ & $221^{* *}$ & $219^{* *}$ & $944-1180^{*}$ & - & $41-59 *$ & $33-40^{*}$ \\
PA11 & $36-48^{*}$ & $185^{* *}$ & $183^{* *}$ & $1060-1330^{*}$ & - & $280-320 *$ & $50-55^{*}$ \\
PEBA72 & - & $181^{* *}$ & $182^{* *}$ & 510 & $>300$ & $290-375 *$ & 56 \\
PEBA63 & - & $176^{* *}$ & $176^{* *}$ & 285 & $>300$ & $450-548 *$ & 53 \\
PEBA40 & -65 & $150^{* *}$ & $151^{* *}$ & 71 & $>300$ & $379-785 *$ & 40
\end{tabular}

\subsection{Interlaminar Fracture Toughness}

Unidirectional $\left[0^{\circ}\right]_{8}$ laminates with PA11, PEBA40, PEBA63, PEBA72 or PA6 nanofibers in the interlayer as well as virgin laminates without nanofiber reinforcements were manufactured by VARTM using UDO ES500 unidirectional glass fiber plies (500 g/ $\mathrm{m}^{2}$, E-glass, SGL Group) and a double steel flat mould. The nanofibers were directly spun onto the reinforcing plies facing the midplane. The epoxy resin (EPIKOTE MGS RIMR135) and hardener (EPIKURE MGS RIMH137) were used in a 100:30 mass ratio. After infusion two different curing cycles were used. In the twostep curing cycle, first a 24 hour dwell step was applied at $20^{\circ} \mathrm{C}$ and $50 \%$ relative humidity, followed by a second curing step at $80^{\circ} \mathrm{C}$ for $15 \mathrm{~h}$. In the one-step curing cycle, curing at $80^{\circ} \mathrm{C}$ for $15 \mathrm{~h}$ was initiated immediately after resin impregnation of the composite. The laminates had a nominal thickness of $3 \mathrm{~mm}$. The production of the PA6 nanofiber toughened composites is described in our previous work [5]. The mode I IFT is evaluated by the Double Cantilever Beam (DCB) test according to ASTM D5528. Samples were prepared according to a previously reported procedure $[4,5,15,21]$. The mode II IFT is determined by End Notched Flexure (ENF) experiments according to a previously reported procedure [4,5,21]. Multiple SEM images were taken to study the fracture surface of DCB and ENF loaded specimens. 


\section{Results and discussion}

\subsection{A novel low-toxicity solvent system for PA11 and PEBA's}

Polyamides like PA6 and PA6.9 are easily electrospun based on a formic acid / acetic acid (FA/AA) solvent system [12,13,32]. However, due to the large nonpolar parts in the PA11 polymer backbone, the FA/AA solvent system is not suitable for PA11-based polymers. Therefore, we developed a new solvent system based on the combination of two miscible solvents to improve the solvency of the polyamides while avoiding any toxic halogenated solvents. A synergistic effect in solvency can be obtained by using a solvent blend because one solvent may help to dissolve the more polar amide groups and the other accounts for the long alkane parts [26,30]. Preliminary solubility tests were performed in solutions combining FA with a large set of 30 solvents that were selected based on hazard profile and Hansen Solubility Parameters. The combination with anisole (An) showed the best solubilising performance and was optimized by turbidimetry which resulted in an optimized solution of $60 \% \mathrm{FA} / 40 \% \mathrm{An}$; SI - S1 [30,33].

\subsection{Electrospinning different morphologies of PA11 and PEBA nanofibers}

One of the advantages of the FA/An solvent system is that it allows a wide range of polymer concentrations to be solvated for each of the PEBA as well as the PA11 polymers. Depending on the exact solution (polymer type and concentration), fibers with diameters ranging from $50 \mathrm{~nm}$ to $800 \mathrm{~nm}$ as well as neat circular or thicker flat ribbon-shaped fibers were produced (Figure 1).

Overall, solutions with the lowest polymer concentration lead to fine nanofibers with a circular cross-section, which increases in radius with increasing concentration. Note nanofibers were obtained with a diameter down to $50 \mathrm{~nm}$ when electrospinning PA11 at low concentrations. This is substantially lower than the typically obtained diameters for polyamides in literature and, therefore, it could also be of interest for other applications besides composites such as filtration $[5,6,34]$. Comparing the nanofibers electrospun at the same polymer concentrations shows PA11 and PEBA40 nanofibers are the finest while PEBA72 nanofibers have the largest diameter. When electrospinning at higher polymer concentrations, the circular cross-section changes, resulting in a ribbon-like morphology of the fibers (e.g. 16\% PEBA72, Figure 1). During the electrospinning process, the solvent on the outside of the jet evaporates upon which the polymer solution on the interface with the air dries out. After fiber deposition, the remaining solvent in the core of the fiber evaporates as well and the fiber collapses, resulting in a flat ribbon structure [26]. 


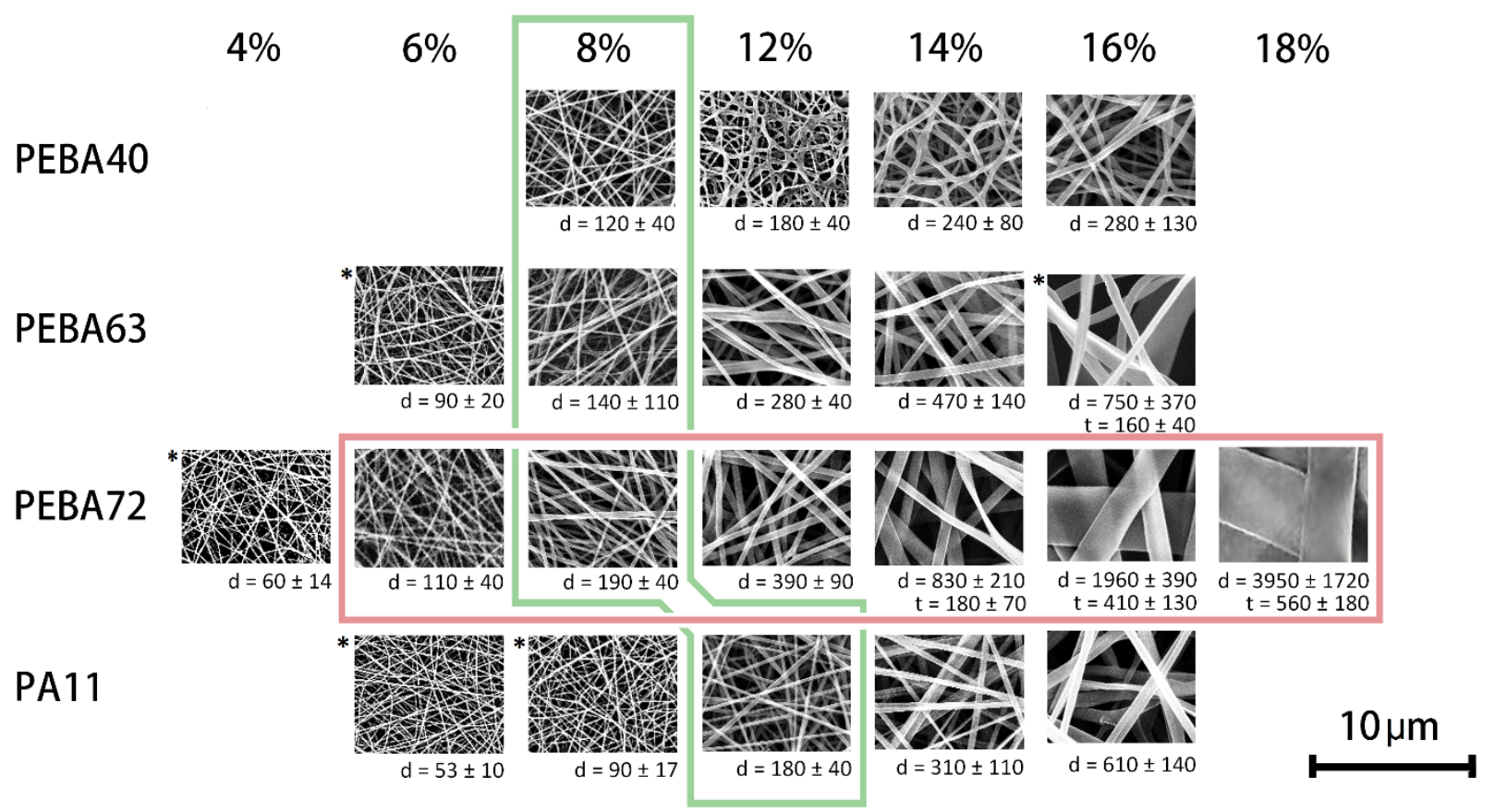

Figure 1 SEM images showing the Influence of the polymer type and polymer concentration on the nanofiber morphology. "d" is the average diameter/width of the fibers in $\mathrm{nm}$. " $\mathrm{t}$ " is the thickness of the ribbons in $\mathrm{nm}$. Overall, solutions with the lowest polymer concentration lead to fine nanofibers with a circular cross-section, which increases in radius with increasing concentration. When electrospinning at higher polymer concentrations, the circular cross-section changes, resulting in a ribbonlike morphology of the fibers. For the areas left blank, no stable electrospinning was possible. All nanofibers were used for composite toughening, except for those noted with $(*)$ due to insufficient electrospinning stability. The influence of polymer type on the IFT of nanofibres with constant diameter (green frame) is discussed in section 3.3.1. The influence of fiber morphology (pink frame) on the IFT is discussed in section 3.3.2.

The differences in fiber morphology are also reflected in the higher specific fiber surface area (Sf) for fine nanofibers (e.g. $21 \mathrm{~m}^{2} / \mathrm{g}$ for $8 \%$ PEBA 72) in comparison to the much lower specific fiber surface area for thicker nanofibers (e.g. $10 \mathrm{~m}^{2} / \mathrm{g}$ for $12 \%$ PEBA 72) or for ribbon-shaped microfibers (e.g. $3.6 \mathrm{~m}^{2} / \mathrm{g}$ for $18 \%$ PEBA 72 ), as calculated by the formula proposed by Eichhorn et al. [32] taking into account the cross-sectional shape (Figure 2). A low nanofiber diameter gives clearly rise to a high Sf. Hence, the nanofibers spun from low wt $\%$ solutions are possibly much more effective at toughening composites since they allow much more interaction with the matrix resin when embedded in the composite. Similarly, the cross-sectional area varies considerably as well, for example from $0.028 \mu \mathrm{m}^{2}$ for $8 \%$ PEBA 72 nanofibers to $2.1 \mu \mathrm{m}^{2}$ for ribbon-shaped $18 \%$ PEBA 72 microfibers.

These aspects are important to relate the effectiveness of a certain nanofiber system for the toughening of composites to its fibrous morphology, as discussed in Section 3.3.2. Based on one single solvent system and polymer family, we can now investigate the influence of mechanical properties (increasing stiffness for the range PEBA polymers), fiber diameter and morphology on the composite's interlaminar fracture toughness (IFT). 


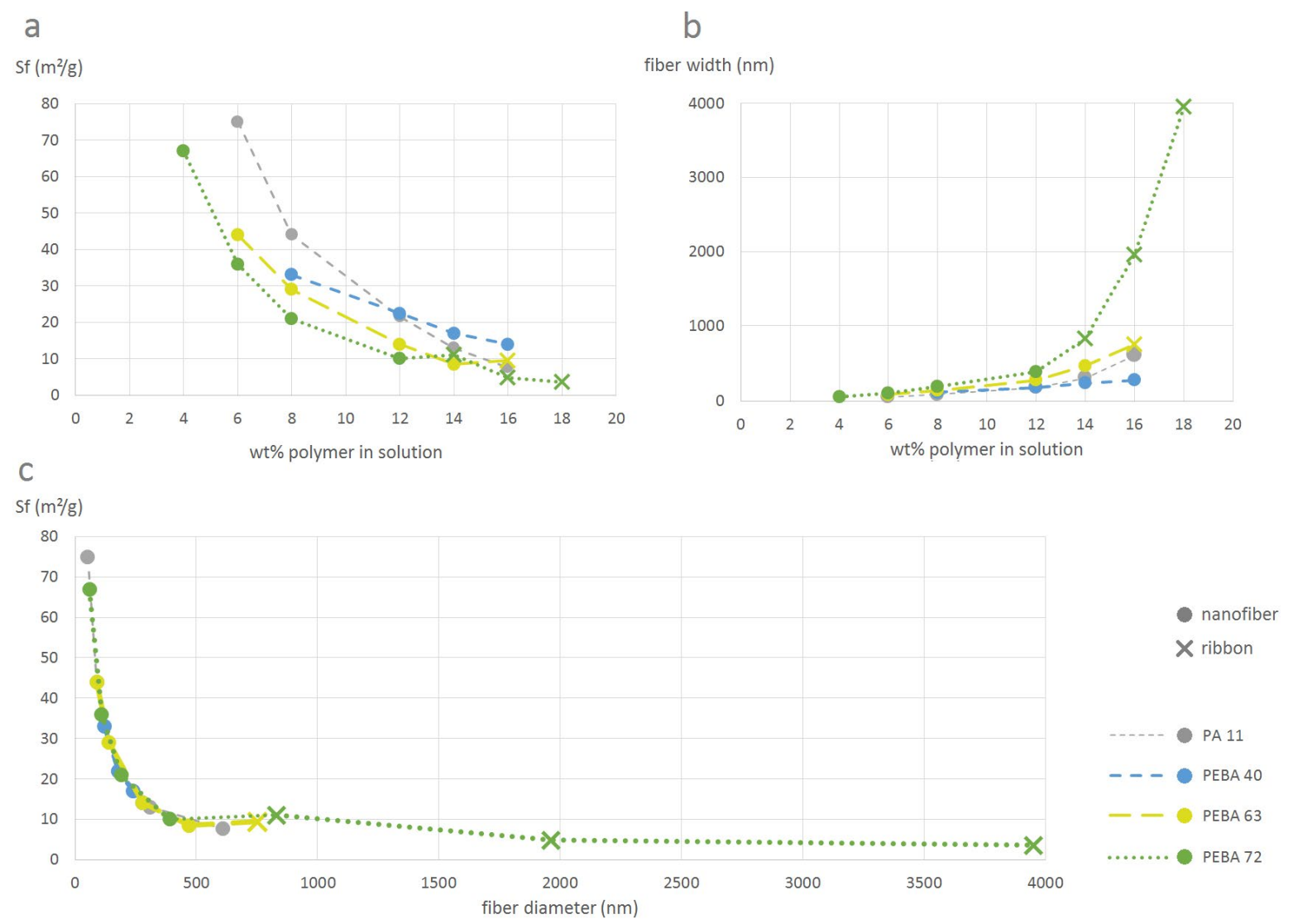

Figure 2 The specific fiber surface area (Sf) and fiber width of electrospun nanofibers are compared with the polymer concentration of the solution they originate from. Clearly, the Sf strongly increases when lowering the wt\% polymer in the electrospinning solution (a) which allows much more interactions with the epoxy matrix when embedded in the composite. In Figure $\mathbf{2 b}$ the high increase of fiber width with increasing polymer concentration becomes very apparent. For the PA11/PEBA nanofiber system the ribbon morphology (denoted with X) starts to emerge at fiber diameters of 750nm and above (b,c). Figure c clearly shows that small diameters are essential for obtaining a high Sf.

\subsection{Delamination performance of interleaved composites (mode I and mode II interlaminar fracture toughness)}

\subsubsection{Influence of the polymer type}

Figure 3 illustrates the effectiveness of each PA11-based polymer system for toughening a composite laminate using interleaves with similar fibrous morphologies (cross-sectional area and Sf). It's immediately clear that PA11-based nanofibers have a positive effect on both the mode I and mode II fracture toughness in comparison to a non-toughened composite. The high ductility and adequate adhesion with the epoxy matrix of the fine PA11 and PEBA nanofibers with diameters in the range of $100-200 \mathrm{~nm}$ results in a mode I IFT up to $600 \mathrm{~J} / \mathrm{m}^{2}$ and the mode II IFT up to $3300 \mathrm{~J} / \mathrm{m}^{2}$. Such improvements are seldom achieved with other single polymer nanofiber systems $[5,11,20,35]$. Polymers like PCL provide similar increases in toughness as PEBA and PA11 [4,5]. Yet, with melting points from $150^{\circ} \mathrm{C}$ up to $185^{\circ} \mathrm{C}$, these PA11-based nanofibers have a much higher temperature stability than $\mathrm{PCL}\left(\mathrm{Tm} \approx 55^{\circ} \mathrm{C}\right)$, allowing integration into high-temperature curing 
resins. Note that the selected resin system [EPIKOTE MGS RIMR13 \& EPIKURE MGS RIMH137] is an already high toughness epoxy resin that is used in wind turbine manufacturing, showing that even inherently tough resins benefit from nanofibrous interleaves.
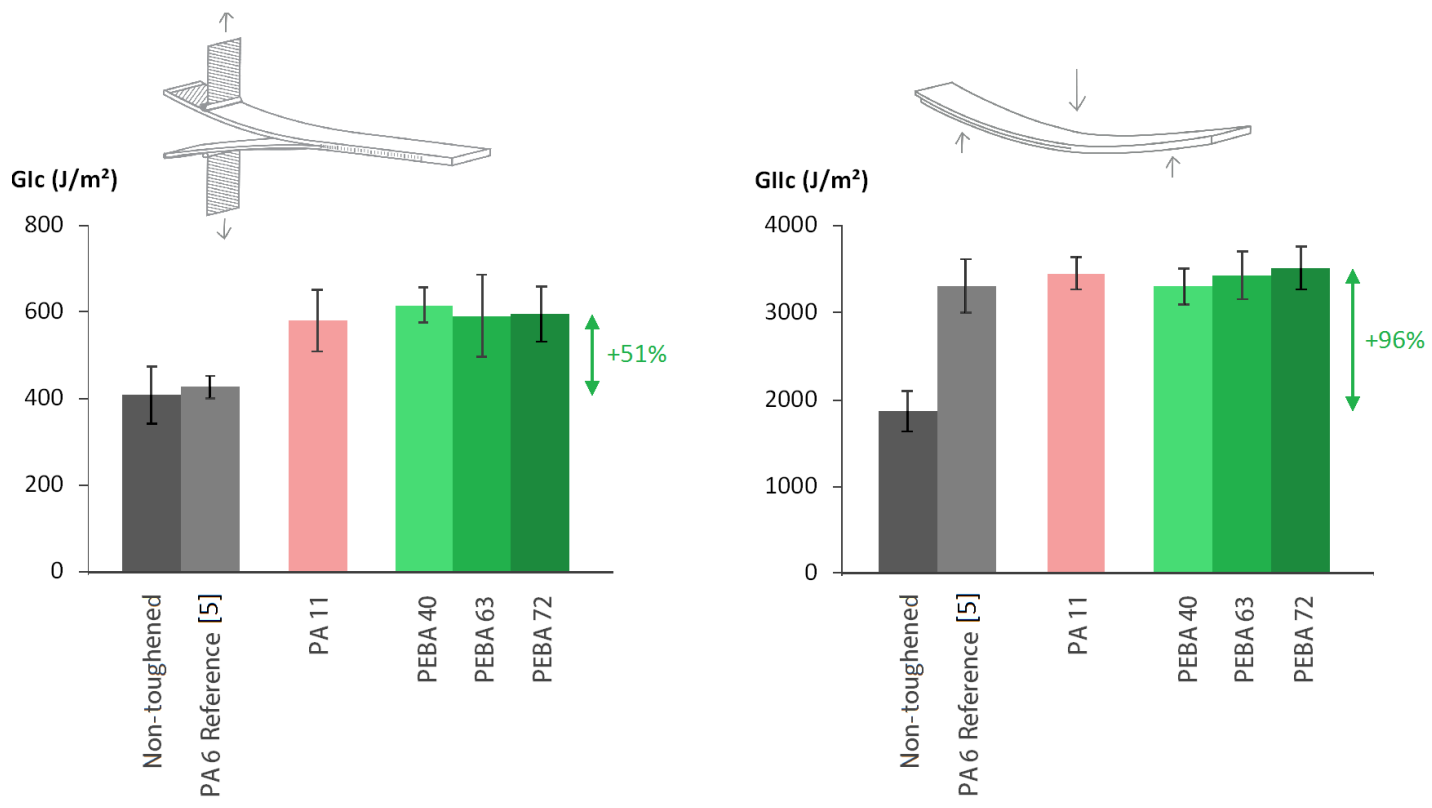

Figure 3: A comparison of the mode I and mode II IFT of PA6 [5], PA11 and PEBA nanofiber-reinforced composites (for the nanofibers shown in the green frame in Figure 1). All nanofiber types except PA6, provide a similar high increase in mode I fracture toughness when compared to a non-reinforced reference composite (the largest p-value is 0.039 for the four PA11 based nanofibers, one tailed T-test, $\alpha=\mathbf{0 . 0 5}$ ). For all nanofiber reinforced composites the mode II IFT is up to $80 \%$ higher than a non-reinforced composite (the largest $p$-value is $\mathbf{0 . 0 1 3}$ for the four PA11 based as well as the PA6 nanofibers, one tailed Ttest, $\alpha=0.05$ )

The increase in fracture toughness of the PA11 and PEBA nanotoughened composites can be related to their mechanical behaviour. Indeed, our previous research on SBS nanofibres shows that a high mode I IFT of interleaved composites can be correlated with a relatively high elongation at break of the nanofibers $(150-500 \%)$, while for this system a high mode II IFT is reached at for polymers with a higher stiffness $(>60 \mathrm{MPa})$ [4,14,21]. Nevertheless, for tuning of the mechanical properties of the SBS-nanofibres an additional chemical treatment with in-house synthesized reactants is necessary which makes commercial production not realistic. The properties of PA11 and PEBA polymer are in the optimal mechanical range, and thus, each of the produced nanofiber interleaves results in a high improvement of the delamination resistance.

Post mortem analysis of mode I delaminated samples, Figure $4 \mathrm{c}, \mathrm{d} \& \mathrm{e}$, shows that frequent interlaminar crossings occur in the delamination path for each system, while the delamination is mainly located at the reinforcing ply boundary. We know from previous research that these crossings are crucial to create nanofiber bridging zones that increase the delamination resistance by straining and fracture of the nanofibers [4-7,14]. Analysis of these zones indeed show plastically deformed nanofibers protruding from the surface. Similarly, the fracture surface of mode II delaminated specimens show the same occurrence of interlaminar crossings resulting in the improved GIIc. 


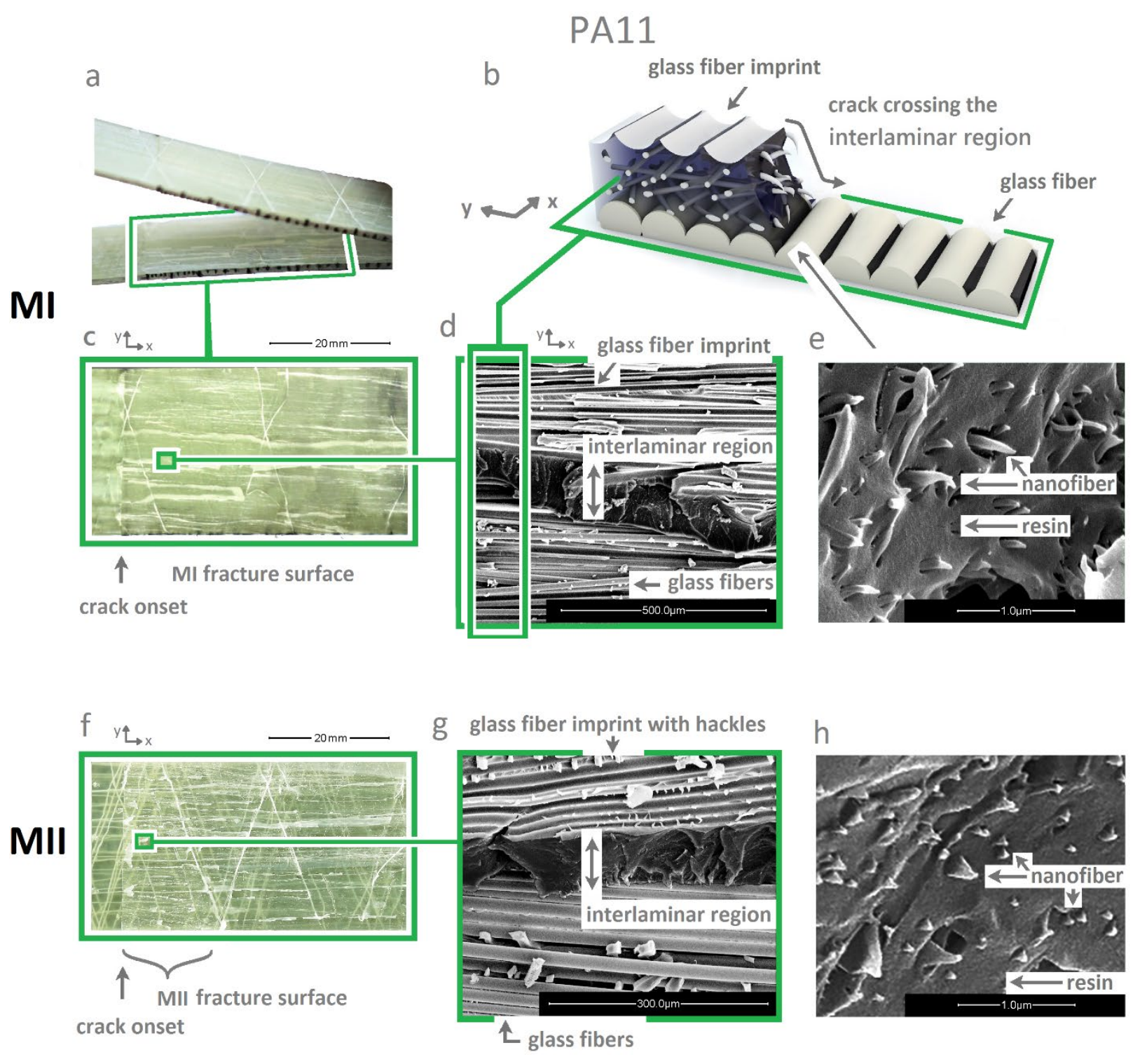

Figure 4. The fracture surface of a mode I (a,b,c,d,e) and mode II (f,g,h) PA11 nanofiber-toughened composite is shown. (a,c,f) show an optical image of a PA11 nanofibre toughened composite with the crack propagating in the $x$-direction. (d,e,g,h) depict an SEM image of the crack path crossing the interlaminar nanofiber-toughened region. In figures (d) and (g), the pale coloured areas on the top and bottom side show both neighbouring reinforcing plies, while in the dark section in-between, the crack crosses through the nanofiber-toughened epoxy layer. In figure (g) more hackles are noted in comparison to (d), which is a typical mode II failure feature. (b) displays a 3D visualisation of the crack crossing the PA11 nanofiber-toughened interlayer. A close-up on the fracture surface $(e, h)$ shows very similar large plastic deformations of the PA11 nanofibers that result in the high increase in fracture toughness of the composite. 
Interestingly, the fracture surface of delaminated specimens toughened with the PA11-based nanofibers is completely different to those toughened with PA6 nanofibers that we studied previously [5,14], see Figure 5. Although similar in nanofiber diameter and cross-sectional shape, the PA6 nanofibers barely result in an improvement of the mode I IFT as the adhesion with the matrix is insufficient [14]. For PA6 toughened composites, the delamination path is situated almost completely within the nanofiber modified interlayer (Fig 5a), but due to debonding of the nanofibers almost no energy is absorbed (Fig 5d). On the other hand, for the PA11 and PEBA toughened composites, smaller crossings are observed (Fig 5b-c), but the nanofibers show plastic deformation without signs of debonding (Fig 5e-f). Thus, this indicates that the higher stiffness and smaller elongation at break of PA6 compared to PEBA and PA11 (Table 1), together with a difference in nanofiber/matrix adhesion, is likely the main cause why the long-chain polyamides have a much better performance under mode I delamination loading.
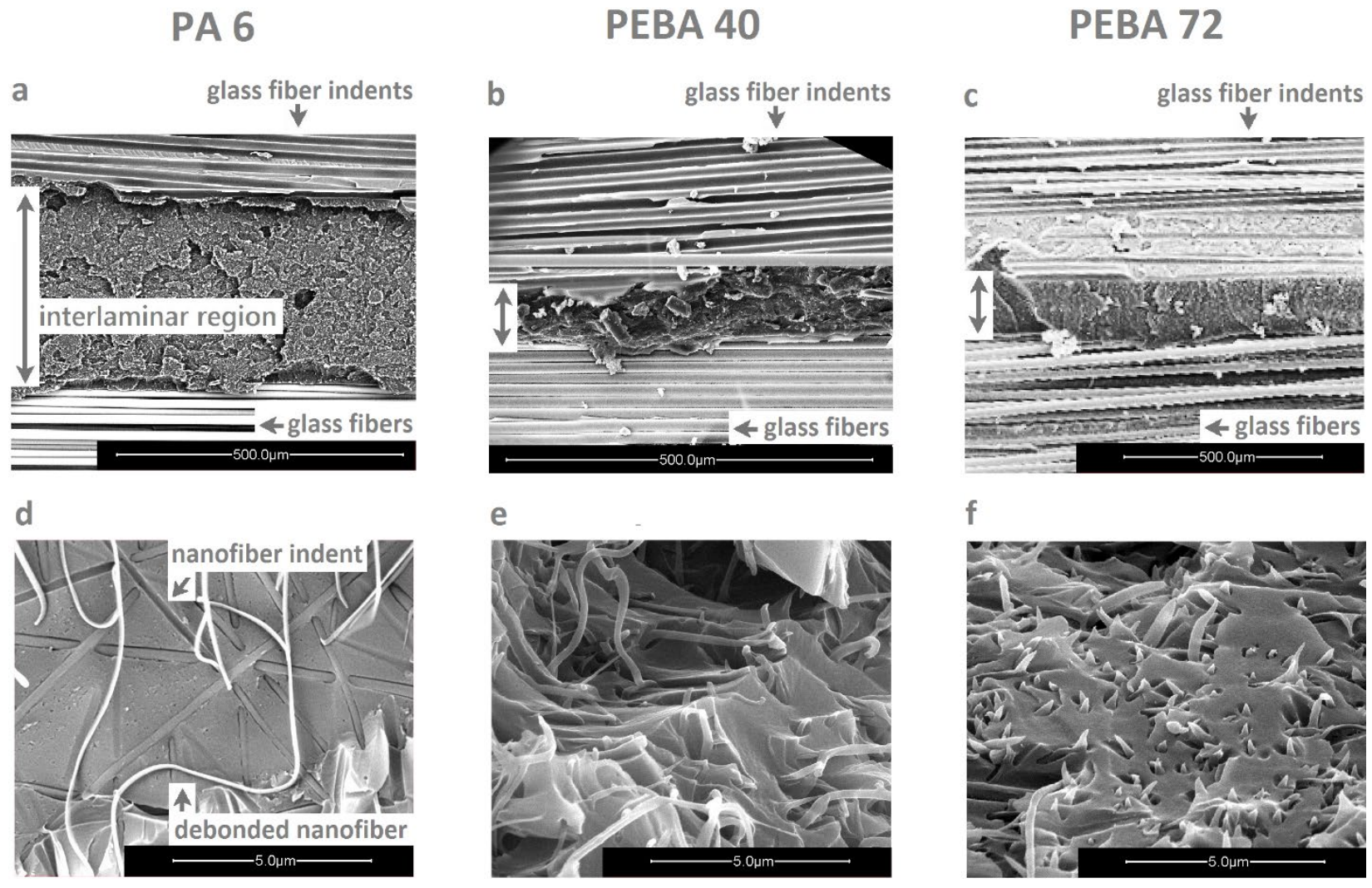

Figure 5. A comparison of the mode I fracture surface of PA6 (a,d), PEBA40 (b,e) and PEBA72 (c,f) nanofiber toughened composites. A large plateau through the interlaminar region is seen for PA6, while the crack transverses relatively sudden through the interlayer (double arrow) for PEBA 40 and PEBA 72 nanofiber toughened composites similar to PA11 in Figure 4d. A close-up of the fracture surface of the PA6 nanofiber-toughened interlayer (d) shows that low interactions between the nanofibers and the matrix material cause the nanofibers to peel off and actually promote delamination. These flat interlayer plateaus that are reminiscent of poor delamination properties are totally absent for PEBA (b,c) and PA11 (Figure 4d) nanofiber toughened composites. A close-up of the PEBA fracture surface $(e, f)$ shows clear plastic deformations of the nanofibers without signs of debonding which indicates a high energy absorbing fracture mechanism. 


\subsubsection{Influence of fiber morphology}

Staying within a specific polymer system, increasing the polymer concentration in the electrospinning solution results in larger nanofibers that go from a cylindrical to a ribbon-like shape (Figure 1, horizontal pink frame). In general, thin round nanofibers resulted in the largest IFT increases (Figure 6). With increasing fiber diameter, there is a slight downwards trend of the IFT visible, but the nanofibers still result in a significant improvement of both mode I and mode II IFT. The decrease in IFT between thin and thicker nanofibers with a circular cross-sectional shape is explained by their decrease in specific surface area (e.g. $40 \mathrm{~m}^{2} / \mathrm{g} \mathrm{vs} 10 \mathrm{~m}^{2} / \mathrm{g}$ for $100 \mathrm{~nm}$ and 400 $\mathrm{nm}$ nanofibers) which in turn results in less interfacial bonding (per volume) between the nanofibers and the matrix (Fig 6c-d). When the cross-sectional shape changes to ribbon-like, the improvement in IFT decreases considerably. Indeed, PEBA 72 fibers with ribbon morphology even decrease the IFT to beneath the non-modified reference value.

Analysis of the fracture surface of delaminated specimens showed that the ribbon-shaped fibers locally mimic closely stacked non-adhering polymer films. Indeed, the flat morphology causes relatively large zones where fibers overlap (ribbon-ribbon interface) between which cracks are free to propagate in the in-plane direction (Figure 7a-e), ultimately lowering the delamination resistance. In addition, larger forces are needed to deform thicker nanofibers, which promotes fibermatrix debonding over plastic deformation. This causes composites toughened with thicker nanofibers such as $390 \mathrm{~nm}$ PEBA 72 to induce a similar crack delamination behaviour as we previously obtained for PA6 nanofibers (Figure 7f,g). 


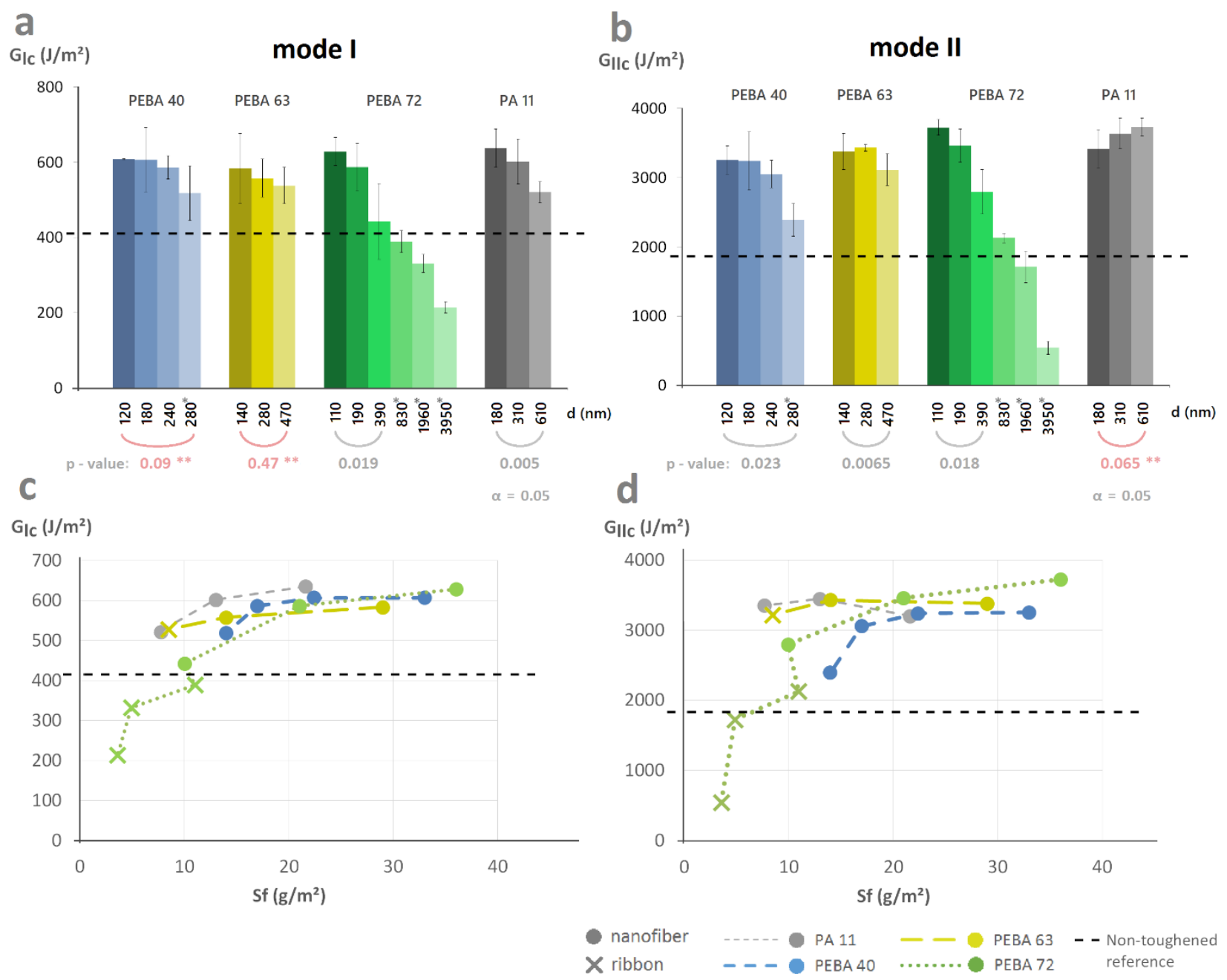

Figure 6: The mode I $(a, c)$ and mode II (b,d) IFT is shown of composites reinforced with different PEBA and PA11 electrospun morphologies both compared with the fiber diameter/width $(a, b)$ as well as the specific fiber surface area (Sf) (c,d). Fine nanofiber-toughened composites provide major IFT improvements in comparison to the non-toughened reference composite (dashed line). The veils with larger diameter fibers (and lower Sf) provide a less significant IFT increase and ribbon shaped fibers (*) with an even lower Sf are even detrimental for the composite's IFT. In the majority of cases the decrease in IFT with increasing fibre diameter is statistically significant (one-tailed T-test, $\alpha=0.05$, $p$-value indicated below the brackets in the graph ), while the observed decreasing trend of GIC for PEBA40 and PEBA63 and the apparent increasing trend for the GIIC of PA11 interleaved specimens is not statistically significant (one-tailed T-test, $\alpha=0.05, * *$ ). 


\section{ribbons}

a

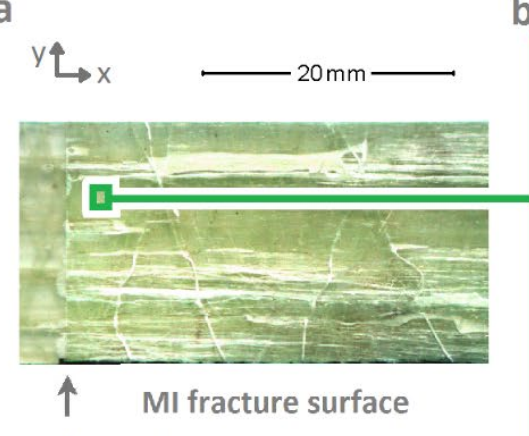

crack onset

d closely stacked ribbons

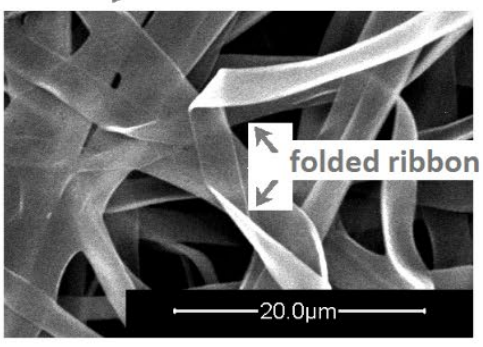

b

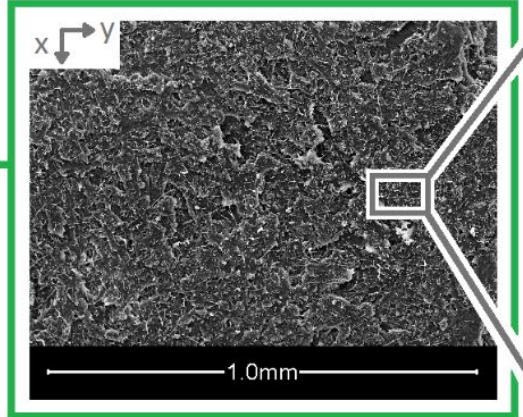

$\mathrm{G}_{\mathrm{Ic}}$ ribbon $<\mathrm{G}_{\mathrm{Ic}}$ non-toughened $210 \mathrm{~J} / \mathrm{m}^{2}<410 \mathrm{~J} / \mathrm{m}^{2}$

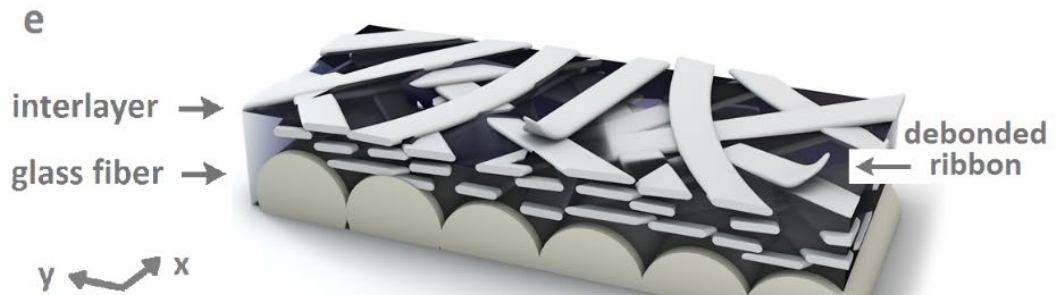

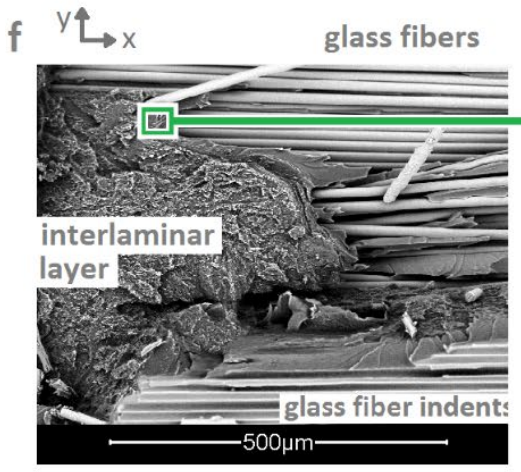

\section{thick nanofibers}

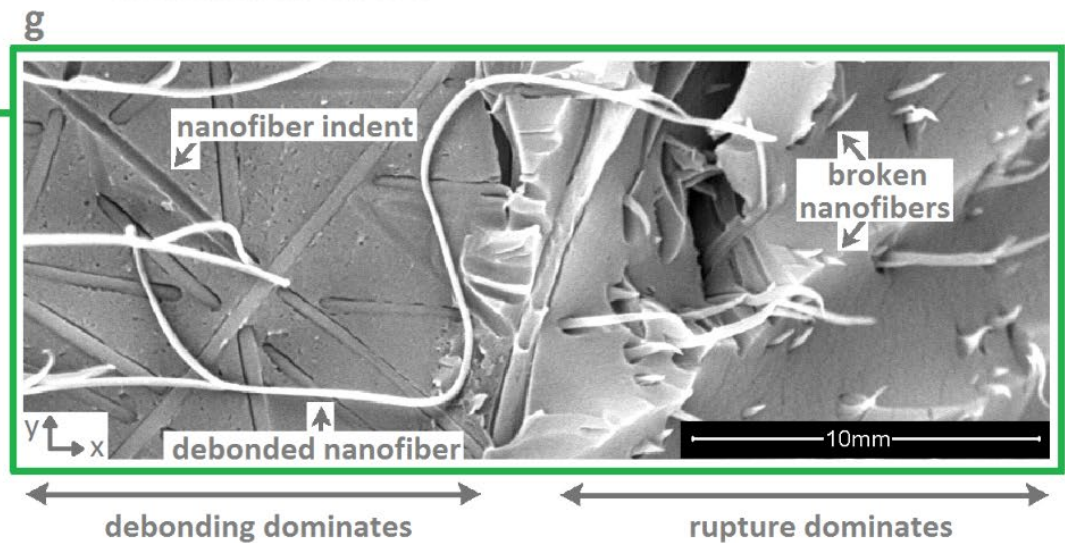

Figure 7. On top, the fracture surface is shown of a mode I tested composite specimen interleaved with $3950 \mathrm{~nm}$ wide PEBA72 ribbons $(a, b, c, e)$ as well as the ribbons (d) prior to composite production. The crack propagates easily in the $x$-direction through the interlaminar region due to the low bonding strength of the ribbon-ribbon and ribbon-epoxy interface. Therefore, no bare glass fibers are visible, but only ribbons and epoxy $(b, c)$. Similarly, in mode II tested composites the crack mainly propagates through the interlaminar region. Composites interleaved with thick nanofibers $(390 \mathrm{~nm})$ show a transient behaviour between thin nanofiber toughened composites and ribbon interlayed composites $(f, g)$. There are fracture zones that are dominated by nanofiber debonding as well as fracture zones where cleavage of nanofibers prevails (g). 


\subsubsection{Influence of high curing temperature on the interlaminar fracture toughness}

The previous sections clearly showed that the PA11-based nanofiber system resulted in a good delamination performance, under both mode I and mode II loading conditions, similar to what we previously achieved using PCL nanofibers [4,5,15]. The advantage of using PA11-based nanofibers is their much higher inherent temperature stability $\left(\mathrm{Tm}=150^{\circ} \mathrm{C}-190^{\circ} \mathrm{C}\right.$, see Table 1$)$ compared to $\mathrm{PCL}\left(\mathrm{Tm}=55^{\circ} \mathrm{C}\right)$. This allows to immediately cure the interleaved composite laminates at elevated temperatures $\left(\mathrm{T}>60^{\circ} \mathrm{C}\right)$ as is done in many industrial settings. PCL nanofibers immediately melt and dissolve into the epoxy matrix resin [36] when cured at elevated temperatures resulting in a loss of the nanofibrous morphology as well as bad mode II delamination resistance (Figure 8). On the contrary, the nanofibrous morphology of PA11-based nanofibers is retained in the final structure and a good mode I and mode II delamination performance are obtained. This is shown in Figure 8 for $12 \mathrm{wt} \%$ PEBA 40 and $8 \mathrm{wt} \%$ PEBA72 nanofiber interleaved composites cured using two different curing cycles: immediately cured at $80^{\circ} \mathrm{C}$ after infusion $(1$ STEP) and 24-hour dwell-step at room temperature followed by a post-cure at $80^{\circ} \mathrm{C}(2-\mathrm{STEP})$. Note that the 2-STEP procedure is the same curing cycle that we used in previous research to retain the PCL nanofibrous morphology $[4,5,15]$. SEM analysis performed on the fracture surface of delaminated specimens showed clear presence of nanofibers, thus confirming that they did not dissolve/melt during the curing of the composites. Hence, these experiments show that the temperature stability of our nanofibers is certainly sufficient to allow many composite manufacturing routes, with a possibility to go to a more temperature stable variant (e.g. PA11 or PEBA72) where necessary.
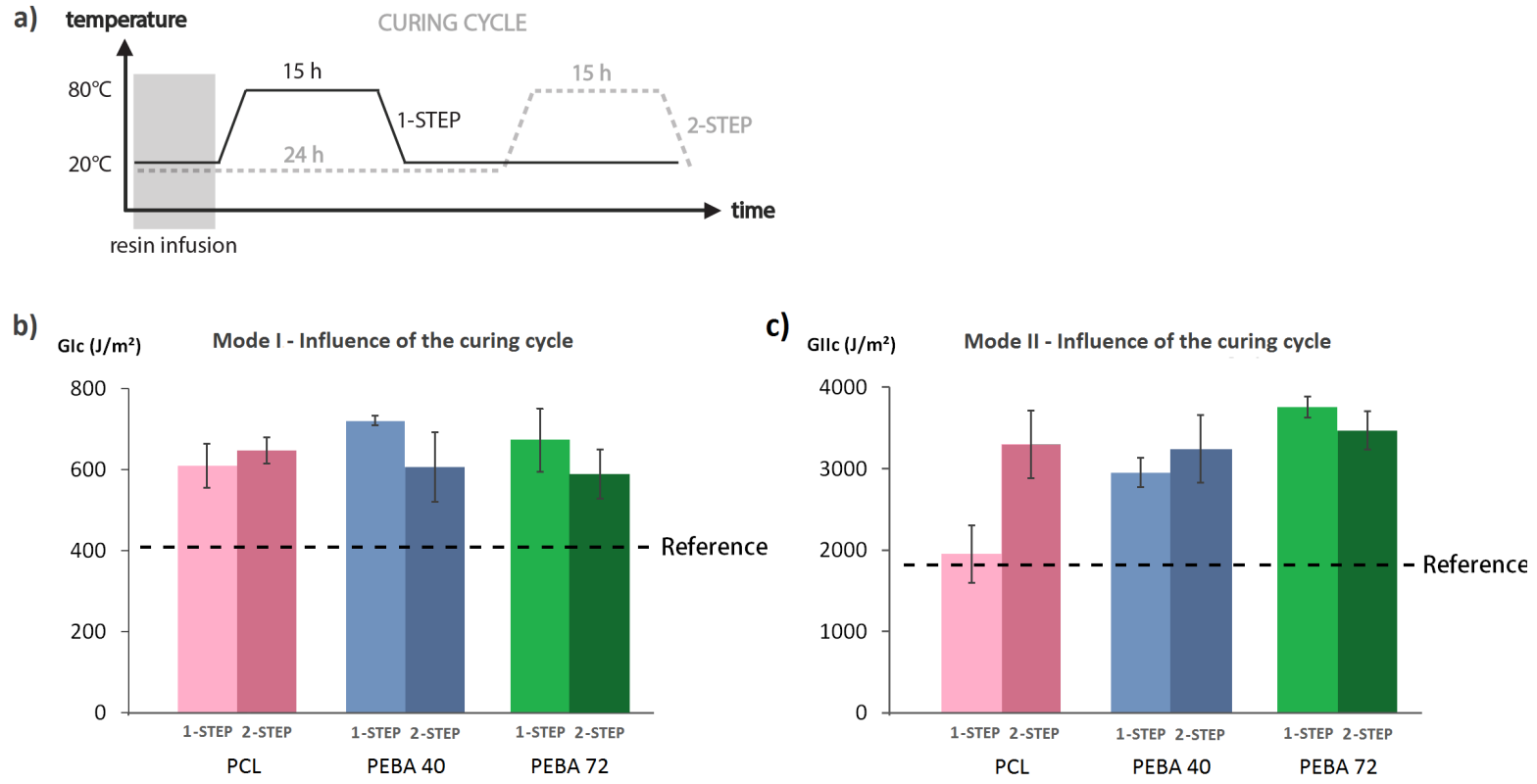

Figure 8: Two different curing cycles are applied to the nanofiber toughened composites (a). In the one-step curing cycle, curing at $80^{\circ} \mathrm{C}$ is immediately initiated after composite impregnation, while in the two-step curing cycle the curing at $80^{\circ} \mathrm{C}$ is preceded by a 24-hour dwell step at room temperature. The influence of the curing cycle on (b) the mode I IFT and (c) the mode II IFT for PCL, PEBA40 and PEBA72 nanofibers is analysed. It is clear that composites toughened with PEBA40 and PEBA72 perform well in both the mode I IFT and mode II IFT regardless of the curing cycle. The PCL toughened composite only performs well in mode II IFT when a two-step curing cycle is applied. Only for the case of PCL in mode II there is a statistically significant difference in IFT between the one-step and two-step cured composites $(p=0.0018, \alpha=0.05$, two-tailed T-test). 


\section{Conclusions:}

This paper describes the first nanofibrous system for composite toughening that has good temperature stability and provides tough composites with a simultaneous high increase in both mode I \& II interlaminar fracture toughness, all from a commercially viable polymer system. As such, this work is a big step ahead for the current state of the art as it allows going towards general interleave systems for high efficiency toughening of composite laminates.

Bio-based polyamide 11 and poly(ether-block-amide) are successfully electrospun through a novel eco-friendly solvent system which allows to vary the morphology of the nanofibers from ultrathin nanofibers with a diameter down to $50 \mathrm{~nm}$ until ribbon-shaped fibers up to $4 \mu \mathrm{m}$ in width by varying the polymer concentration. The solvent system is based on formic acid and anisole, both non-toxic, non-halogenated solvents, whose combination results in an increased solvency for the long-chain polyamide family.

Composites interleaved with different nanofiber morphologies clearly show that the morphology, both diameter and cross-sectional shape, has a major impact on the composite's IFT. It is important to use sufficiently thin round nanofibers as they lead to high mode I and mode II IFT increases while the IFT decreases when thicker nanofibers are used and is even detrimental in the case of ribbons.

Analysis of the fracture mechanisms show that the fiber morphology affects the crack path. Indeed, ribbon shaped fibers result in weak zones at overlapping fiber points where delaminations can easily grow. In contrast, very fine round nanofibers are less prone to debonding (more surface area per volume) and result in effective nanofiber bridging zones that increase the IFT substantially. Additionally, PEBA and PA11 nanofibers possess a relatively high intrinsic temperature resistance $\left(\mathrm{Tm}=150^{\circ} \mathrm{C}-185^{\circ} \mathrm{C}\right)$ which allows for good IFT improvements, even when cured at elevated temperatures, highly relevant for a wide commercial applicability.

Overall, the proposed system for composite toughening allows for a flexible choice of polymer nanofibers depending upon the application. PA11 nanofibers result in a fully bio-based system with the highest temperature stability, where the PEBA's are very suitable for higher production rates due to a more stable electrospinning process at higher solution throughput. The PA11/PEBA-based nanofibers thus are an ideal platform that provides a unique combination of a straightforward ecofriendly electrospinning of a commercially available polymer, a high temperature resistance and an outstanding toughening performance in both mode I (+51\%) and mode II (+96\%) IFT. This will open up future commercial applications where toughening is needed both in well established epoxy resins as well as novel bio-sourced epoxy systems. Further, by the addition of nanofibers, the composite structures will be produced lighter, because no weight is added, while improving the design criteria (higher delamination resistance). 


\section{Acknowledgements}

Results in this paper were obtained within the framework of the IWT Strategic Basic Research Grant 141344, BOF 13/24J/020 and BOF.PDO.2015.0028.01 project.

\section{Data Availability}

The raw data required to reproduce these findings cannot be shared at this time as the data also forms part of an ongoing study. The processed data required to reproduce these findings cannot be shared at this time as the data also forms part of an ongoing study.

\section{Bibliography}

[1] J.S. Kim, D.H. Reneker, Mechanical properties of composites using ultrafine electrospun fibers, Polym. Compos. 20 (1999) 124-131. doi:10.1002/pc.10340.

[2] K. Bilge, E. Ozden-Yenigun, E. Simsek, Y.Z. Menceloglu, M. Papila, Structural composites hybridized with epoxy compatible polymer/MWCNT nanofibrous interlayers, Compos. Sci. Technol. 72 (2012) 1639-1645. doi:10.1016/j.compscitech.2012.07.005.

[3] K. Bilge, Y. Yorulmaz, F. Javanshour, A. Ürkmez, B. Y1lmaz, E. Şimşek, M. Papila, Synergistic role of in-situ crosslinkable electrospun nanofiber/epoxy nanocomposite interlayers for superior laminated composites, Compos. Sci. Technol. 151 (2017) 310-316. doi:10.1016/j.compscitech.2017.08.029.

[4] S. van der Heijden, L. Daelemans, T. Meireman, I. De Baere, H. Rahier, W. Van Paepegem, K. De Clerck, Interlaminar toughening of resin transfer molded laminates by electrospun polycaprolactone structures: Effect of the interleave morphology, Compos. Sci. Technol. 136 (2016) 10-17. doi:10.1016/j.compscitech.2016.09.024.

[5] L. Daelemans, S. Van Der Heijden, I. De Baere, H. Rahier, W. Van Paepegem, K. De Clerck, Damage-Resistant Composites Using Electrospun Nanofibers: A Multiscale Analysis of the Toughening Mechanisms, ACS Appl. Mater. Interfaces. 8 (2016) 11806-11818. doi:10.1021/acsami.6b02247.

[6] L. Daelemans, S. van der Heijden, I. De Baere, H. Rahier, W. Van Paepegem, K. De Clerck, Nanofibre bridging as a toughening mechanism in carbon/epoxy composite laminates interleaved with electrospun polyamide nanofibrous veils, Compos. Sci. Technol. 117 (2015) 244-256. doi:10.1016/j.compscitech.2015.06.021.

[7] L. Daelemans, S. van der Heijden, I. De Baere, H. Rahier, W. Van Paepegem, K. De Clerck, Using aligned nanofibres for identifying the toughening micromechanisms in nanofibre interleaved laminates, Compos. Sci. Technol. 124 (2016) 17-26. doi:10.1016/j.compscitech.2015.11.021.

[8] B. De Schoenmaker, S. van der Heijden, S. Moorkens, H. Rahier, G. van Assche, K. De Clerck, Effect of nanofibres on the curing characteristics of an epoxy matrix, Compos. Sci. Technol. 79 (2013) 35-41. doi:10.1016/j.compscitech.2013.02.009.

[9] R. Palazzetti, A. Zucchelli, Electrospun nanofibers as reinforcement for composite laminates materials - A review, Compos. Struct. $182 \quad$ (2017) 711-727. doi:10.1016/j.compstruct.2017.09.021.

[10] Y.A. Dzenis, D.H. Reneker, Delamination Resistant Composites Prepared by Small 
Diameter Fiber Reinforcement at Ply Interfaces. United States Patent 6265333, 2001.

[11] J. Zhang, T. Yang, T. Lin, C.H. Wang, Phase morphology of nanofibre interlayers: Critical factor for toughening carbon/epoxy composites, Compos. Sci. Technol. 72 (2012) 256-262. doi:10.1016/j.compscitech.2011.11.010.

[12] B. De Schoenmaker, L. Van Der Schueren, Ö. Ceylan, K. De Clerck, Electrospun polyamide 4.6 nanofibrous nonwovens: Parameter study and characterization, J. Nanomater. 2012 (2012). doi:10.1155/2012/860654.

[13] B. De Schoenmaker, S. Van Der Heijden, I. De Baere, W. Van Paepegem, D. Clerck, 2013 - Effect of electrospun polyamide 6 nanofibres on the mechanical properties of a glass fibre epoxy composite, (n.d.) 1-11.

[14] L. Daelemans, N. Kizildag, W. Van Paepegem, R.D. Dagmar, K. De Clerck, Interdiffusing core-shell nanofiber interleaved composites for excellent Mode I and Mode II delamination

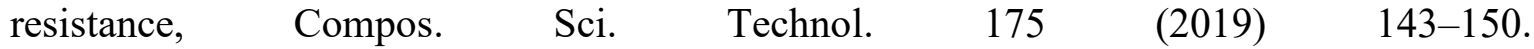
doi:10.1016/j.compscitech.2019.03.019.

[15] S. van der Heijden, L. Daelemans, B. De Schoenmaker, I. De Baere, H. Rahier, W. Van Paepegem, K. De Clerck, Interlaminar toughening of resin transfer moulded glass fibre epoxy laminates by polycaprolactone electrospun nanofibres, Compos. Sci. Technol. 104 (2014) 66-73. doi:10.1016/j.compscitech.2014.09.005.

[16] L. Daelemans, W. Van Paepegem, R.D. Dagmar, K. De Clerck, Excellent Nanofiber Adhesion for Hybrid Polymer Materials with High Toughness Based on Matrix Interdiffusion During Chemical Conversion, $1807434 \quad$ (2019) 1-10. doi:10.1002/adfm.201807434.

[17] M.R. Dadfar, F. Ghadami, Effect of rubber modification on fracture toughness properties of glass reinforced hot cured epoxy composites, Mater. Des. 47 (2013) 16-20. doi:10.1016/j.matdes.2012.12.035.

[18] C. Monteserín, M. Blanco, N. Murillo, A. Pérez-Márquez, J. Maudes, J. Gayoso, J.M. Laza, E. Aranzabe, J.L. Vilas, Effect of different types of electrospun polyamide 6 nanofibres on the mechanical properties of carbon fibre/epoxy composites, Polymers (Basel). 10 (2018). doi:10.3390/polym10111190.

[19] T. Brugo, R. Palazzetti, The effect of thickness of Nylon 6,6 nanofibrous mat on Modes III fracture mechanics of UD and woven composite laminates, Compos. Struct. 154 (2016) 172-178. doi:10.1016/j.compstruct.2016.07.034.

[20] G.W. Beckermann, K.L. Pickering, Mode i and Mode II interlaminar fracture toughness of composite laminates interleaved with electrospun nanofibre veils, Compos. Part A Appl. Sci. Manuf. 72 (2015) 11-21. doi:10.1016/j.compositesa.2015.01.028.

[21] S. van der Heijden, L. Daelemans, K. De Bruycker, R. Simal, I. De Baere, W. Van Paepegem, H. Rahier, K. De Clerck, Novel composite materials with tunable delamination resistance using functionalizable electrospun SBS fibers, Compos. Struct. 159 (2017) 1220. doi:10.1016/j.compstruct.2016.09.057.

[22] S. Hamer, H. Leibovich, A. Green, R. Intrater, R. Avrahami, E. Zussman, A. Siegmann, D. Sherman, Mode i interlaminar fracture toughness of Nylon 66 nanofibrilmat interleaved 
carbon/epoxy laminates, Polym. Compos. 32 (2011) 1781-1789. doi:10.1002/pc.21210.

[23] L. Daelemans, S. van der Heijden, I. De Baere, H. Rahier, W. Van Paepegem, K. De Clerck, Improved fatigue delamination behaviour of composite laminates with electrospun thermoplastic nanofibrous interleaves using the Central Cut-Ply method, Compos. Part A Appl. Sci. Manuf. 94 (2017) 10-20. doi:10.1016/j.compositesa.2016.12.004.

[24] J. Zhang, T. Lin, X. Wang, Electrospun nanofibre toughened carbon/epoxy composites: Effects of polyetherketone cardo (PEK-C) nanofibre diameter and interlayer thickness, Compos. Sci. Technol. 70 (2010) 1660-1666. doi:10.1016/j.compscitech.2010.06.019.

[25] J.S. Stephens, D.B. Chase, J.F. Rabolt, Effect of the electrospinning process on polymer crystallization chain conformation in nylon-6 and nylon-12, Macromolecules. 37 (2004) 877-881. doi:10.1021/ma0351569.

[26] K. Behler, M. Havel, Y. Gogotsi, New solvent for polyamides and its application to the electrospinning of polyamides 11 and 12, Polymer (Guildf). 48 (2007) 6617-6621. doi:10.1016/j.polymer.2007.08.058.

[27] M. Havel, K. Behler, G. Korneva, Y. Gogotsi, Transparent thin films of multiwalled carbon nanotubes self-assembled on polyamide 11 nanofibers, Adv. Funct. Mater. 18 (2008) 2322 2327. doi:10.1002/adfm.200800106.

[28] M. Dhanalakshmi, J.P. Jog, Preparation and characterization of electrospun fibers of Nylon 11, Express Polym. Lett. 2 (2008) 540-545. doi:10.3144/expresspolymlett.2008.65.

[29] M. Dhanalakshmi, A.K. Lele, J.P. Jog, Electrospinning of Nylon11: Effect of processing parameters on morphology and microstructure, Mater. Today Commun. 3 (2015) 141-148. doi:10.1016/j.mtcomm.2015.01.002.

[30] C.M. Hansen, Hansen Solubility Parameters: A user's handbook, Second, Taylor \& Francis Group, LLC, Boca Raton, 2007.

[31] M.D. Abràmoff, P.J. Magalhães, S.J. Ram, Image processing with imageJ, Biophotonics Int. 11 (2004) 36-41. doi:10.1117/1.3589100.

[32] B. De Schoenmaker, A. Goethals, L. Van Der Schueren, H. Rahier, K. De Clerck, Polyamide 6.9 nanofibres electrospun under steady state conditions from a solvent/non-solvent solution, J. Mater. Sci. 47 (2012) 4118-4126. doi:10.1007/s10853-012-6266-9.

[33] D. Prat, A. Wells, J. Hayler, H. Sneddon, C.R. Mcelroy, S. Abou-shehada, P.J. Dunn, CHEM21 selection guide of classical- and less classical-solvents, (2016) 288-296. doi:10.1039/c5gc01008j.

[34] J.. Deitzel, J. Kleinmeyer, D. Harris, N.. Beck Tan, The effect of processing variables on the morphology of electrospun nanofibers and textiles, Polymer (Guildf). 42 (2001) 261-272. doi:10.1016/S0032-3861(00)00250-0.

[35] H. Saghafi, A. Zucchelli, R. Palazzetti, G. Minak, The effect of interleaved composite nanofibrous mats on delamination behavior of polymeric composite materials, Compos. Struct. 109 (2014) 41-47. doi:10.1016/j.compstruct.2013.10.039.

[36] A. Cohades, L. Daelemans, C. Ward, T. Meireman, W. Van Paepegem, K. De Clerck, V. Michaud, Size limitations on achieving tough and healable fibre reinforced composites through the use of thermoplastic nanofibres, Compos. Part A Appl. Sci. Manuf. 112 (2018) 
485-495. doi:10.1016/j.compositesa.2018.07.002. 